\title{
School Context, Gender, and Delinquency
}

\author{
Josefina Fiqueira-McDonough'
}

Received January 31, 1985; accepted January 21, 1986

This study compares two high schools serving the same community and compares student bodies with similar background characteristics. The purpose is to examine how control/strain variables predict delinquency in two distinct school contexts. It was found that minor delinquency occurred more often in the environment dominated by competitive academic achievement, routine handling of discipline, and unpredictable supervision. Examination of the model paths suggest that this environment is also conservative and unlikely to offer legitimate opportunities to girls with gender-egalitarian orientation. The school context characterized by a broader definition of success, more specialized discipline, and predictable supervision promotes stronger bonds with its students and lower levels of delinquency for both genders.

\section{BACKGROUND TO THE RESEARCH QUESTION}

This paper explores the impact of school context on the misbehavior of adolescent males and females. The formulation of the research question is based on postulates derived from previous studies:

1. Adolescence is a crucial period for the crystallization of gender identity (Condry, 1974; Gold and Petronio, 1980; Parsons, 1976).

The research reported here was funded by Grant 79-JN-AX-0030 from the Office of Juvenile Justice and Delinquency Prevention in the Law Enforcement Assistance Administration, U.S. Department of Justice. An earlier version of this paper was presented at the 1984 meeting of the American Society of Criminology in Cincinnati, Ohio.

'Michigan State University and Institute for Social Research, The University of Michigan, P.O. Box 1248, Ann Arbor, Michigan 48106. Received Ph.D. in Sociology and Social Work from the University of Michigan. Research interests include deviance and control, and gender issues. 
2. The school is an important factor in the development of adolescent identity and behavior (Gold and Mann, 1984; Pink, 1984; Polk, 1975).

3. Activities organized within and around the school constitute the most salient behavioral opportunities for adolescents (Kellam et al., 1975, Kelly, 1978; Polk and Schaffer, 1972).

4. The school therefore plays a central role in affecting misbehavior of male and female adolescents (Chester, 1983; Dembo; 1984; Goodland, 1984; Porter et al., 1982; Rist 1970).

Attention to school context has been absent, or at most tenuous, in the extensive literature on crime and disruption in schools (Reubel et al., 1979). There is, nonetheless, a consensus that the school experience is a critical factor in the development of adolescent identity (Pink, 1984; Polk, 1975). Numerous studies show that decisions about students' careers mesh with commonplace organizational practices of schools. These, over time, serve to solidify both in-school and out-of-school identities of the students (Kellam et al., 1975; Kelly, 1978; Pink, 1978; Polk and Schaffer, 1972).

The centrality of the school's influence on adolescents is reinforced by the fact that most social activities provided for the young are organized within and around the school. These activities furnish a wide range of social opportunities, both conventional and deviant (Polk, 1975).

Typically, "school impact studies" either pay little attention to gender differences or do not include girls in their samples. Delinquency (and school achievement) has been perceived, for the most part, as predominantly a male issue. The resurgence of the women's movement has encouraged research on female achievement and deviance in the last decade and a half. Still, studies in these areas usually focus on psychological motivation and family socialization as primary predictors (Parsons et al., 1976).

Organizations, especially public organizations, might successfully resist change (Meyer and Rowan, 1977). Public organizations such as schools are vulnerable to external pressures, but they also need to maintain legitimacy by demonstrating a modicum of efficiency. They will often engage in ritual compliance to environmental demands while maintaining the functional routines that have in the past produced predictable outcomes. This implies that examination of the functional structure is crucial to the assessment of gender equality in school opportunities (Kaufman and Richardson, 1982). ${ }^{2}$

\footnotetext{
${ }^{2}$ Recent assessments of the progress toward gender-equalization reveal that, on the one hand, considerable normative change has occurred (Herzog and Bachman, 1982; Mason et al., 1976; Parelius, 1975; Screiber, 1978; Thornton and Freedman, 1979; Thornton et al.,1983). On the other hand, stagnation on the socioeconomic front is evident (Matthei, 1982; Powell and Jacobs, 1984; Treiman and Hartman, 1981). This suggests that the emerging norms are not filtering through the organizations that establish opportunities. The lag in organizational adjustment to new demands is consistent with some models of change (e.g., Parsons et al., 1976); it might be argued that, given time, organizations will become more egalitarian. On the other hand, they mi ht $k=$ ir timtors of res tanno
} 
In sum, different school contexts, to the extent that they offer different opportunities, are likely to affect student behavior in general as well as to impact differentially on male and female students.

\section{LIMITATIONS OF PAST SCHOOL STUDIES}

Given the evidence mentioned, it appears that intervention at the school level holds great promise for affecting adolescent behavior. Investigation of the effect of school context on behavior should therefore be a cornerstone for social policies with regard to delinquency control. That so much more research on adolescent deviant behavior has focused on family and community structure than on schools might be attributed to the lack of success of large-scale studies ${ }^{3}$ in isolating school effects on student performance (Coleman, 1969, 1972; Flanagan, 1962; Goodman, 1959; Johnston, 1973; Shaicoft, 1967).

A careful examination of these studies (Johnston, 1973) shows that they suffer from problems of measurement, design, and analysis. For example, school characteristics are often assessed through students' perception and rarely focus on structural dimensions (Flanagan, 1962); samples are almost always drawn from the student population rather than from a sampling frame of schools, often resulting in very low numbers of students per school (Coleman, 1969); and organizational indicators may be created through datareduction strategies yielding orthogonal dimensions rather than contextual constructs (Johnston, 1973). Typical problems found in these studies include the failure to separate community from school effects (Flanagan, 1962; Goodman, 1969) and background from school effects (Coleman, 1969; Johnston, 1973). While the community/school separation can be resolved by purposive sampling and careful design, the second problem is more complex and more susceptible to interpretative solutions. The logic commonly used in separating background and school effects follows the temporal principle of causation. Since background dimensions antecede the school experience and school effects are reduced to insignificance when background characteristics are controlled for, the inference is that school effects on performance are spurious.

The "priority" of background factors does not, however, preclude school characteristics, with which they are correlated, from having effects

\footnotetext{
${ }^{3}$ An important exception is the study of British schools by Rutter et al. (1979), which set out to measure the effects of organizational dimensions on high-school students' behavior. Contrary to school impact studies in the United States, Rutter and his colleagues paid close attention to the contextual profiles of the schools. Furthermore, the longitudinal design of the study permitted the assessment of the "added-on" effect of the school as distinct from individual arhievement ot a eiven $r$ " $n t$ in time
} 
that are causally independent of, yet statistically correlated with, them. ${ }^{4}$ Nonetheless, interpretation of findings in which background factors predominate reinforces a favorite American interpretation: that individual characteristics best explain individual performance, and that such characteristics are overwhelmingly the outcome of family socialization. This confirmation of a cultural tendency toward individual reductionism and early socialization determinism diverts attention from the investigation of other social institutions and their salience in different phases of the life cycle.

\section{THE PREDICTIVE MODEL}

Considerable data have been gathered to substantiate the relationship between academic performance and delinquency (Elliott and Voss, 1974; Figueira-McDonough, 1983; Hargreaves, 1967; Mann, 1981; Polk and Schaffer, 1972; Stinchcombe, 1964). The interpretation of this relationship has typically followed two alternative theories. On the one hand, control theorists construe the association as resulting from a lack of attachment to school and significant others associated with school goals (e.g., parents and teachers), which leaves students vulnerable to illegitimate temptations. On the other hand, a few criminologists still hold to a strain explanation, arguing that poor academic performance bars students from status and school-related opportunities, leading them to search for compensatory achievement through illegitimate opportunities.

Although in the last decade control theories have been dominant in delinquency research (Aultman, 1979), there are clear signs of a reassertion of the strain interpretation (Bernard, 1984). A group of scholars has recently argued that the two interpretations are not antithetical but can advantageously be integrated in the same explanatory model (Eve, 1978; Figueira-McDonough and Selo, 1980; Johnson, 1979).

The model proposed in Figure 1 follows this perspective. It combines strain, bond, and opportunity factors related to the school. It proposes that aspirations condition the perceived importance of the school. This orientation will in turn be translated into school involvement, both academic and nonacademic. Detachement from school (bond-erosion) and performance failure (frustration) are expected to lead to delinquency insofar as illegitimate opportuniteis are available. Consistent with the purpose of investigating gender differences within each school context, indicators of gender-egalitarian

\footnotetext{
${ }^{4}$ Since most schools serving the black population are also likely to have meager resources, it is unlikely that in a national random sample deviant cases will be represented in sufficient number to permit a clear separation between race and school characteristics. In instances such as these, purposive samples can be much more useful.
} 


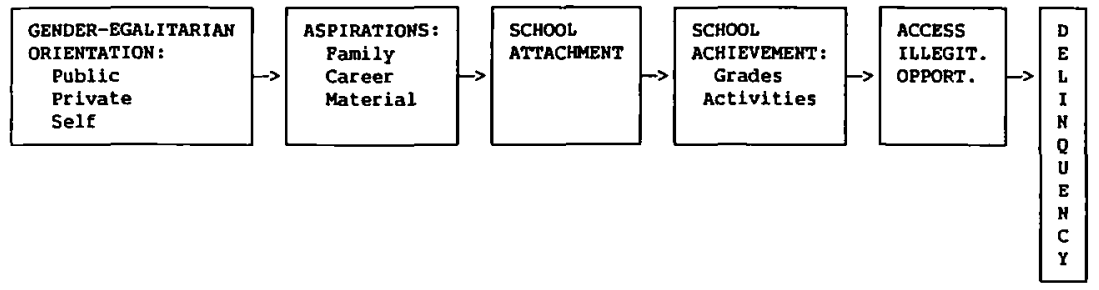

Fig. 1. Theoretical model.

attitudes are included in the model. It is expected that such attitudes will affect aspirations, as well as the type of behavior that male and female students will consider suitable to become involved in (Barton and FigueiraMcDonough, 1985; Figueira-McDonough, 1984).

\section{METHODOLOGY}

\section{The Sample}

This exploratory study was designed to compare how males and females misbehave in two different school contexts. To circumvent the problem of confounding community and school effects, two schools serving the same community were selected. The second criterion in the choice of the schools was the similarity in the background of the students. The design approaches a quasi-experiment, in which community and background characteristics are controlled for, while the school context differs (Chester, 1983). Consistent with the exploratory purpose of the study, this design enhances the examination of a specific pattern of relations (predictive model) in two situations while precluding generalization (Kellam et al., 1975; Runkel and McGrath, 1972).

The cross-sectional nature of the data has obvious limitations. Feedback effects on the specified model cannot be assessed. ${ }^{5}$ With this qualification in mind, estimating how the model predicts delinquency at a given time, within two different school contexts, is a feasible and worthwhile enterprise.

Community and Background Characteristics. The schools in this study were chosen from a sample of a larger project conducted in 1980 in a midwestern state (Barton et al., 1982; Figueira-McDonough et al., 1981). Self-reported data were obtained from a random sample of tenth graders

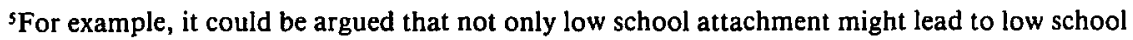
performance, but also that low school performance might lower school attachment. 
in nine schools. About 2,000 students answered a self-administered questionnaire that took one hour to complete. The questionnaire included items on behavior (conforming and deviant), aspirations, school involvement, attitudes, family background, etc. Principals, assistant principals, and counselors filled out a self-administered questionnaire and were interviewed. In both instances, information about the organizational functioning of the school was solicited. School reports and student handbooks were used to check for consistency.

Two schools were selected for the present study, covering a subsample of 350 students. They serve an urban upper middle-class community. At the time the study was conducted, the median family income in this community was $\$ 46,000$; the average home value was $\$ 100,000$. Comparison of the background characteristics of the two student bodies confirms their socioeconomic similarity. There are no significant differences between the two samples in terms of race, father's and mother's occupation, father's and mother's education, class, ${ }^{6}$ and family composition. The two samples are almost entirely white, predominantly living with both parents who have for the most part some college education and professional or semiprofessional occupations.

School Profiles. There are many similarities between the schools, in part reflecting the fact that they serve a rather homogeneous upper middleclass community. Both schools are academically successful: dropout rates are low, and the percentage of students going to college is high. The resources available to the schools - budget per student, teacher training and pay, and equipment - are quite similar. Through questionnaires sent to the principals, vice principals, and counselors, systematic information was obtained on the organization of the schools, the priority given to different goals, the pattern of participation in the formulation and implementation of rules, the definition of the most serious problems, and the discipline process and strategies of control. This information is summarized in Table I. Enough differences were found between the two schools to characterize them as distinctive contexts for student activity. The school which emphasizes academic success is referred to as TOPS and the more diversified school as CENTRAL.

While academics are given strong emphasis in both schools, and discipline and civic-mindedness are cited as important, respondents rank these goals differently by school. For TOPS the most important goal is defined as "teaching the 3 r's," while in CENTRAL developing intellectual ability through stimulating interest in learning, promoting emotional maturity, and offering vocational choices is the first priority. Similarly, students' problems in TOPS are defined by reference to academic performance, while in CEN-

'The class indicator was obtained by combining the level of education and occupation of the parent who acted as head of household (for details, see Barton et al., 1982). 
Table I. School Characteristics

\begin{tabular}{|c|c|c|}
\hline & TOPS & CENTRAL \\
\hline Goals & Academic achievement & $\begin{array}{l}\text { Learning motivation } \\
\text { Maturation } \\
\text { Vocational training }\end{array}$ \\
\hline Setting of rules & Nonspecialized & Specialized \\
\hline Discipline process & Formal undifferentiated & $\begin{array}{l}\text { Differentiated } \\
\text { Nonserious - informal } \\
\text { Serious-formal }\end{array}$ \\
\hline Problems & $\begin{array}{l}\text { Related to failure to } \\
\text { perform academically }\end{array}$ & $\begin{array}{l}\text { Related to adjustment: } \\
\text { school, peers, family, } \\
\text { community }\end{array}$ \\
\hline Supervision & $\begin{array}{l}\text { Vary with teacher } \\
\text { Student/teacher ratio } .25 \\
\text { Policeman on the } \\
\text { grounds one hour }\end{array}$ & $\begin{array}{l}\text { Formal corridor supervision } \\
\text { Student/teacher ratio } .17 \\
\text { Policeman has } \\
\text { headquarters at school }\end{array}$ \\
\hline
\end{tabular}

TRAL attention is paid to peer, family, and community factors. Class discipline is considered more important at TOPS and it is assigned as the responsibility of all staff, while both the formulation and implementation of rules are far more specialized in CENTRAL, depending on place and behavior.

A parallel differentiation, permitting tailored responses, is seen in the gradation of the disciplinary process in CENTRAL. While TOPS deals formally, through the assistant principal, with all types of misbehavior, CENTRAL deals informally with minor offenses and calls the police for the most serious. On the other hand, the environment at CENTRAL is more predictable. Student-teacher interaction is uniformly formal, while it varies greatly by teacher at TOPS. The higher teacher ratio, the existence of corridor supervision, and the presence of a police officer on the grounds contribute further to a more controlled context at CENTRAL.

\section{Measures}

The indicators of gender-egalitarian orientation, aspirations, and delinquency are derived from factor analyzing responses of the total sample to questions addressing each of these areas. Cumulative indices were built with the variables that loaded strongly (above .50) on each factor. Simple cumulative indices were used as measures of all other dimensions in the model, except for grades, as indicated below.

Feminist Orientation. The three measures used were obtained from factor analyzing a battery of questions designed to tap the salient spheres in 
the gender-role repertoire targeted for change by the women's movement (Figueira-McDonough, 1985). The resulting three factors are public (covering attitudes towards equal-gender opportunity in work and public leadership), private (including attitudes toward family division of labor and conflict between mother and work roles), and self (composed to self-concepts regarding aggressiveness and success).

Aspirations. Three dimensions emerged from the factor analysis of items addressing future aspirations in education, occupation, ownership, family, and the importance attached to these aspirations. Family aspirations included both plans of marriage and having children. On the career dimension, the importance of future education and the aspiration to a high-status job load high. Finally, the material factor was made up of elements tapping the importance of owning cars, clothes, having money to travel, etc.

School Attachment. This measure is a simple additive index including items regarding importance of school, liking school, importance of grades, identification and liking of teachers, perceived teachers' responsiveness to student, and caring about teachers' opinions of self.

Grades. These were measured in terms of the self-reported previous year's average.

School Activities. This is a simple additive index of the number of school activities (e.g., athletic, musical, literary, scientific, student government, prevocational, etc.) that students report being involved in.

Illegitimate Opportunities. This is measured by an averaged index of the ease (from nearly impossible to very easy on 5-point scale) of access to a variety of illegitimate opportunities (get drugs, get alcohol, sell drugs, get a gun, get into a bar, get birth control pill, get a room for sex, sell stolen goods). ${ }^{7}$

Delinquent Behavior. Respondents reported on a variety of delinquent behaviors in which they might have engaged over the prior year. An 8-point scale - never, once or twice a year, once every 2-3 months, once every 2-3 weeks, once a week, 2-3 times a week, and every day or more - was used. To counter the possibility of excessively high frequency estimates and the resulting problems in linear analysis, the implied frequencies were modified downwards. ${ }^{8}$ The self-reported delinquency items were factor analyzed,

\footnotetext{
${ }^{7}$ Attempts to differentiate between different types of illegitimate activities were unsuccessful since they were highly intercorrelated.

${ }^{8}$ The actual transformation was: never $=0$, once or twice a year $=2$, once every 3-4 months $=4$, once a month $=10$, once every $2-3$ weeks $=18$, once a week or more $=50$. The behavior items list adopted in this study closely resembles the one constructed by Elliott and Ageton (1980) in response to criticisms that past self-reported studies inadequately measured serious delinquent behavior (Hindelang et al., 1979). (For a complete list of the items see FigueiraMcDonough et al., 1981).
} 
Table II. Type of Delinquency by School

\begin{tabular}{|c|c|c|c|c|c|}
\hline & \multicolumn{2}{|c|}{ TOPS } & \multicolumn{2}{|c|}{ CENTRAL } & \multirow{2}{*}{$\begin{array}{l}\text { Significant level } \\
\text { of difference }\end{array}$} \\
\hline & Mean & $S D$ & Mean & $S D$ & \\
\hline Violent & 1.8 & 6.9 & 2.9 & 17.7 & ns \\
\hline Property & 7.9 & 20.6 & 5.1 & 16.2 & ns \\
\hline Minor & 89.2 & 94.6 & 58.7 & 82.7 & .0001 \\
\hline
\end{tabular}

yielding three dimensions: minor delinquency (marijuana use, other drug use, alcohol use, skipping school, lying about age, loitering, driving intoxicated, selling drugs, having sex, and petty stealing), property offenses (stealing, vandalism, breaking and entering, receiving stolen goods), and person offenses (extortion, hitting teacher, serious fight, group fight, aggravated assault, use of weapon). Three indices - in effect, factor scores - were created from the items loading strongly on each dimension.

\section{RESULTS}

\section{Delinquency in Each Setting}

Table II displays the mean frequency of the three types of delinquency by school. Plainly, the frequency of violent crimes is very low in both schools. Although the incidence of property crimes is higher, the difference between the schools is insignificant. We focus, then, on the minor offenses, since their frequency is very high and significantly different between the two schools. The term "delinquency," as used subsequently, will refer to minor offenses."

Table III gives the mean frequency of minor offenses by gender and school. Boys at TOPS high reported considerably more of such behaviors, and girls at CENTRAL high school considerably less than any other group. Differences are significant between all groups except between girls at TOPS and boys at CENTRAL. The pattern of gender differentiation persists within schools, but the level of delinquency is much higher at TOPS. Girls at this school report the same levels of minor delinquency as do boys at CENTRAL. In this instance, the school effect is stronger than the gender effect, offering

\footnotetext{
${ }^{9}$ Although a few students are involved exclusively in minor offenses, the higher the involvement in these offenses the greater the probability of involvement in property and person offenses. Among students reporting 10 or more minor of fenses, $40 \%$ had also committed at least one of the more serious offenses; among those reporting 70 or more minor offenses the percentage of those involved in other offenses as well was $72 \%$. For more details see Figueira-McDonough et al. (1981).
} 
Table III. Minor Delinquency by Sex and School Comparisons Within and Between Schools

\begin{tabular}{|c|c|c|c|c|c|c|c|c|c|}
\hline \multicolumn{2}{|c|}{ TOPS } & \multicolumn{2}{|c|}{ CENTRAL } & \multicolumn{6}{|c|}{ Significance of pairwise differences ${ }^{a}$} \\
\hline Boys & Girls & Boys & Girls & $\mathrm{TB} / \mathrm{TC}$ & $\mathrm{CB} / \mathrm{CG}$ & $\mathrm{TB} / \mathrm{CB}$ & $\mathrm{TG} / \mathrm{CC}$ & $\mathrm{TB} / \mathrm{CG}$ & $\mathrm{TG} / \mathrm{CB}$ \\
\hline 102.0 & 71.4 & 73.4 & 37.3 & .04 & .002 & .02 & .01 & .000 & ns \\
\hline
\end{tabular}

${ }^{a}$ TB, TOPS boys; TG, TOPS girls; CB, CENTRAL boys; CG, CENTRAL girls.

an excellent opportunity to investigate how schools might affect the misbehavior of a sample of girls and boys with very similar backgrounds.

Not only is TOPS the setting of higher delinquency than CENTRAL but the association between gender and delinquency is weaker at TOPS. The two relevant questions then become: (1) Why is delinquency more prevalent at TOPS (school effect)? (2) Why are the traditional gender differences in delinquent behavior smaller at TOPS than CENTRAL (school/gender effect)? To investigate these two issues the model delineated in Fig. 1 was tested with data from each subgroup.

\section{Explanatory Paths for Each Subgroup}

The analysis examines the empirical relationships among the variables in the order specified in the model (Fig. 1). Each variable is regressed on all others assumed to be causally prior. Nonsignificant paths are deleted, and the model is reestimated to produce final path coefficients. The strategy of separate analysis by gender group, proposed by Farnworth and Horan (1980), is carried out. This procedure permits not only comparison of delinquency by sex but adequate investigation of the similarity and dissimilarity of the effects of each predictor on the intervening and outcome variables among gender groups.

The results of the analysis for each subgroup are given in Figures 2 and 3. ${ }^{10}$ Comparison of the major paths for each subsample reveals both differences between and within schools. The significant predictive paths for each group are first described, then school, gender, and gender/school differences are discussed.

Five major paths are identified for the male sample at TOPS. Three of these paths affect delinquency through grades and two through illegitimate opportunities. They can be characterized as follows:

1. Traditional achievement-support for traditional gender roles in private life predicts career commitment. This in turn is associated with high grades and low delinquency.

${ }^{10}$ Nonsignificant paths were deleted. In the only instance where specific level indicators were measured independently (grades and school activities) the intercorrelation was nonsignificant. 
MALES

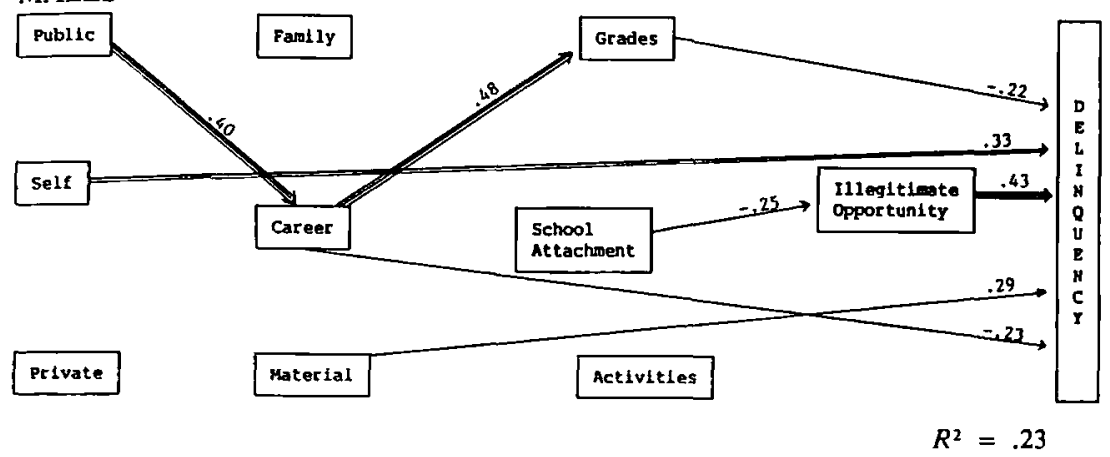

FEMALES

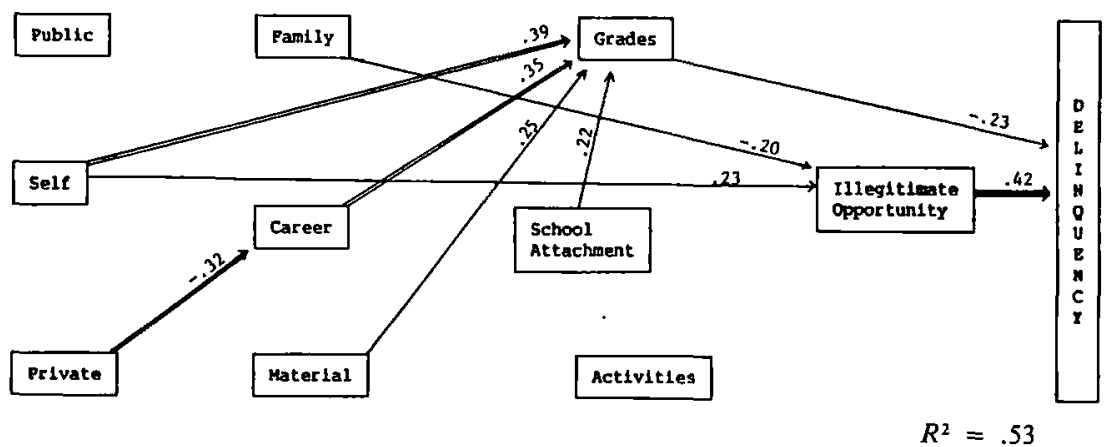

Fig. 2. TOPS.

2. Independent achievement - a strong aggressive and success-oriented self-concept is conducive to good grades and good academic performance. This decreases the probability of delinquency.

3. Immediate rewards - high material aspirations predict poor grades and delinquency.

4. Rebellion-a strong aggressive and successful self-concept also predicts a greater access to illegitimate opportunities and, through it, to high delinquent involvement.

5. Mainstream - a strong commitment to having a family in the future serves as a buffer against illegitimate opportunities and therefore against delinquency involvement.

Among girls at TOPS, of the five paths that emerged from the analysis, two are school-related and three are not:

1. Feminist achievement - this path is similar to the boys' traditional achievement, with the difference that support for gender equality in public roles predicts career commitment. 


\section{MALES}

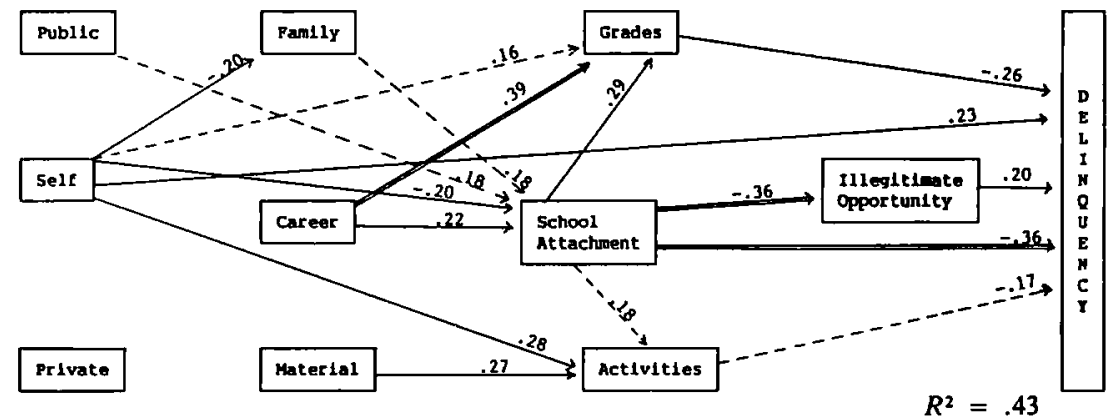

FEMALES

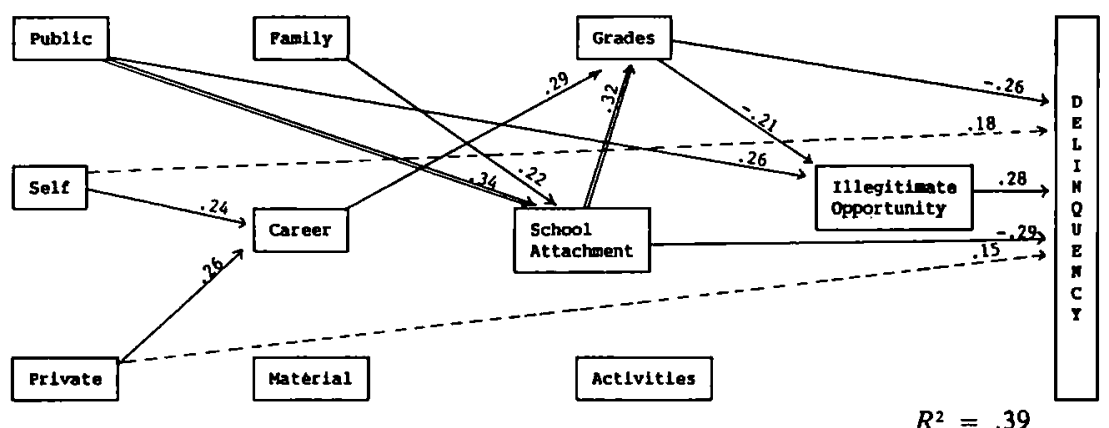

Fig. 3. CENTRAL.

2. Conformism - school attachment restricts access to illegitimate opportunity and, through it, to delinquent behavior.

3. Rebellion-a strong self-concept of aggressiveness and success appear to directly produce deliquent behavior.

4. Ritualism-commitment to a career regardless of achievement serves as a restraint on delinquent involvement.

5. Immediate rewards - high aspirations for material goods are also directly conducive to delinquent behavior.

For males at CENTRAL, four of the five paths are characterized by the significance of one of the school-related variables (school attachment, grades, school activities):

1. Progressive achievement - support for public gender equality predicts school attachment, which in turn predicts academic success, low access to illegitimate opportunity, and low delinquency. 
2. Careerism - strong career commitment through school attachment or directly through grades again decreases the probability of access to illegitimate opportunities and the incidence of delinquent behavior.

3. Alternative rewards-material aspirations are deflected through school activities from producing delinquent behavior.

4. Independent achievement - an aggressive, success-oriented selfconcept can lead to academic achievement, which is inversely related to delinquency.

5. Rebellion - an aggressive success-oriented self-concept also predicts delinquency.

Among girls at CENTRAL, one can identify four major paths:

1. Feminist achievement-although a stronger path than for CENTRAL males, it follows the same sequence of support for genderpublic equality, school attachment, good grades, and low delinquency.

2. Feminist careerism - again this is similar to the path described for males, with the difference that support for gender private equality and aggressive, successful self-concepts are strong predictors of career commitment.

3. Mainstream - the importance of establishing a family in the future predicts school attachment and, through it, both good grades and nondelinquency.

4. Rebelliousness - strong support for private gender equality and aggressive, successful self-concept are positively associated with delinquency.

Cross-school comparisons show that, for both genders at TOPS, the strongest paths underscore the academic goals of the school, in terms of commitment to career and successful performance (grades). On the whole, the paths in the analysis of the CENTRAL samples reveal the greater importance of school-related variables in predicting delinquency among its students, both males and females.

A more detailed examination of the path analyses permits a clear identification of the similarities and differences between school samples. Table IV summarizes all direct effects for the four subsamples. It shows that grades are uniformly important in preventing delinquency in all groups but that school attachment is an important direct buffer for CENTRAL only. In addition, access to illegitimate opportunities is a stronger predictor for TOPS than CENTRAL.

Comparing gender results across schools reveals no systematic differences (Table IV) except to show that gender-egalitarian beliefs and aspira- 
Table IV. Direct Effects of All Predictors on Delinquency

\begin{tabular}{lcccccc}
\hline & \multicolumn{3}{c}{ TOPS } & & \multicolumn{2}{c}{ CENTRAL } \\
\cline { 2 - 3 } \cline { 5 - 6 } & Male sample & Female sample & & Male sample & Female sample \\
& $\beta$ & $\beta$ & & $\beta$ & $\beta$ \\
\hline Illegal opportunity & .42 & .43 & & .20 & .28 \\
Grades & -.23 & -.22 & & -.26 & -.26 \\
Activities & - & - & & -.17 & - \\
School attachment & - & - & & -.36 & -.29 \\
Family aspirations & - & - & & - & - \\
Career aspirations & - & -.23 & & - & - \\
Material aspirations & - & .29 & & - & - \\
Public equality & - & - & & - & - \\
Private equality & - & - & & - & .15 \\
Self-concept & - & .33 & & .23 & .18 \\
\hline
\end{tabular}

tions are more important for girls than boys. Within-school gender comparisons show more clear-cut differences at TOPS than at CENTRAL. The most noteworthy finding is that the model explains over twice as much male than female delinquency at TOPS (.23 vs .53). It is also noteworthy that the gender-egalitarian values that emerge as significant are opposite for each gender at TOPS, traditional for males, egalitarian for females. None of these differences emerge from the analysis of the CENTRAL samples.

To examine school/gender effects we turn to the four-group comparison. In Table II we found that school effects were stronger than gender effects and, from the preceding analysis, that the effect of school attachment is the clearest difference between the two schools. It follows that the optimal strategy for investigating school/gender differences should start with a closer examination of the paths conducive to and emerging from school attachment and other school-related variables.

As shown in Table V, school attachment affects grades, school activities, and illegitimate activities. For all groups except girls at TOPS, school attachment is directly related to grades. However, it is for males at CENTRAL that school attachment is most important, affecting not only grades but school activities as well, and sheltering them from illegitimate opportunities.

The effects of preceding factors on school attachment are shown in

Table V. Effect of School Attachment on Grade, School Activities, and Access to Illegitimate Opportunities

\begin{tabular}{lccccc}
\hline & \multicolumn{3}{c}{ TOPS } & & \multicolumn{2}{c}{ CENTRAL } \\
\cline { 2 - 3 } \cline { 5 - 6 } & $\mathrm{M}$ & $\mathrm{F}$ & & $\mathrm{M}$ & $\mathrm{F}$ \\
& $\beta$ & $\beta$ & $\beta$ & $\beta$ \\
\hline Grades & .22 & - & .29 & .32 \\
School activities & - & - & .18 & - \\
Illegitimate opportunities & - & -.25 & -.36 & - \\
\hline
\end{tabular}


Table VI. Effect of Gender Egalitarian Orientation and Aspirations on School Attachment

\begin{tabular}{lcccc}
\hline & \multicolumn{2}{c}{ TOPS } & \multicolumn{2}{c}{ CENTRAL } \\
\cline { 2 - 6 } & $\mathrm{M}$ & $\mathrm{F}$ & $\mathrm{M}$ & $\mathrm{F}$ \\
& $\beta$ & $\beta$ & $\beta$ & $\beta$ \\
\hline Public & - & - & .18 & .34 \\
Private & - & - & - & - \\
Self & - & - & -.20 & - \\
Family aspirations & - & - & .18 & .22 \\
Career & - & - & .22 & - \\
Material & - & - & - & - \\
\hline
\end{tabular}

Table VI. Gender-egalitarian orientations as well as career orientations are tied to school attachment for students at CENTRAL only. Inspection of the effects of aspirations reveals that career aspirations affects grades independently of school attachment for all groups but most strongly for girls at TOPS. Furthermore, gender-egalitarian values form the strongest predictor of career orientation for this group.

Lastly, the path of independent achievement (self $\rightarrow$ grades) is present for all groups except females at TOPS. That is, males at TOPS and both males and females at CENTRAL, with an aggressive/success self-concept, might follow either an achievement or rebellious path. However, for girls at TOPS with a similar self-concept, only the rebellious path is in evidence.

\section{DISCUSSION}

The model is weakest in explaining male delinquency in TOPS, the context of higher incidence of such behavior. This suggests that the school does not have much effect on the behavior of these young men. It might be that the context atomizes students so that they are more susceptible to a variety of outside conditions and influences. The explanatory power of the model is strong for the other three subsamples and, curiously, strongest for females at TOPS.

Differences in school attachment between CENTRAL and TOPS students help explain their differences in the incidence of delinquency. Students at CENTRAL are more attached to their school; in addition, this attachment effectively restrains them from involvement in delinquency. Furthermore, access to illegitimate opportunities appears to be more restricted at CENTRAL than at TOPS. On the other hand, the achievement path at TOPS fits with its goal priority and convergent definition of success. In an academically competitive environment, grades become the single most important measure of success. 
These findings are consistent with the characteristics of each school context. On the one hand, the single and overwhelming goal of academic achievement seems to serve TOP's reputation more than the students' needs or goals. By comparison, CENTRAL appears to be more diverse in its goals and to take a greater interest in the students' nonacademic needs and diverse vocations. Also important, and tied to this, is TOPS's standardized and uniform way of dealing with discipline, accompanied with a fuzziness of responsibility and a lack of supervision. This stands in contrast to the more differentiated and clear rules, specialized responsibility, and tighter supervision at CENTRAL. These characteristics make CENTRAL a more predictable environment and one that deliberately makes access to illegitimate opportunities more difficult.

The greater importance of gender-egalitarian values in explaining female misbehavior is consistent with findings that indicate the greater adherence to such values by women (Figueira-McDonough, 1985). This gender difference is especially remarkable at TOPS. School achievement (and nondelinquency) is associated with support for traditional gender roles for males and gender-role equality for females. The commitment to a traditional family division of labor shown by the male achievers at TOPS mirrors similar values found among successful male executives who devote undivided attention to their careers (Kreps, 1971; Herzog and Bachman, 1982). Also noteworthy is the finding that the self-concept of aggressiveness and success is least related to delinquency among boys in TOPS and most for girls in the same school. This suggests that TOPS might of fer more legitimate avenues to boys than to girls sharing these characteristics.

The dissociation between school attachment and achievement for female students at TOPS also suggests that their academic performance is not tied to school encouragement but, to a much larger extent than any of the other groups, it is a function of their gender-egalitarian values and personal career commitments.

From the results of the school/gender analysis it appears that students at CENTRAL view the school as more supportive or more instrumental to their attitudes and aspirations than students at TOPS. Egalitarian public aspirations seem to be consistent with school context at CENTRAL, since they predict school attachment, but not at TOPS. The school-related pattern of achievement at TOPS is linked to traditional attitudes for males and feminist attitudes for females, while at CENTRAL for both genders (although stronger for females) this path includes gender-egalitarian orientations.

In sum, differences in school attachment might explain why TOPS has a much higher incidence of delinquency than CENTRAL, and differences in receptivity to gender-egalitarian orientations might explain why girls at TOPS are so much involved in delinquency. 


\section{CONCLUSIONS}

The primary objective of this study has been to investigate differences in delinquency involvement between two schools drawing students from the same socioeconomic background and the same community. In TOPS - a school strongly devoted to its academic reputation, maintaining a highly competitive environment, handling student problems in a rather standardized way and with weak supervision - students are less attached to the school and have greater access to illegitimate opportunities. Conversely, for students in CENTRAL - a school with diversified goals and dealing with problems in a differentiating but predictable fashion as well as offering tight supervision school attachment is stronger and clearly serves as a restraint on delinquent involvement.

Another objective of the study has been to investigate gender/delinquency differences in each school. The results of most self-reported studies of delinquency have consistently shown that, while delinquency involvement is as broad and nonspecialized among girls as among boys, there are large differences in the frequency of such behavior by gender. Males report a much higher involvement in delinquent activity than girls. TOPS female students stand as an exception in this respect, suggesting that TOPS exacerbates the frequency of delinquent activity among girls.

Recent popular explanations of the increase in female delinquency have overwhelmingly linked it to gender-egalitarian (feminist) orientations. As expected, gender-egalitarian orientations are found to be more important for girls than for boys in determining aspirations and subsequent behavior. Although the support for feminist orientation is the same for the two female groups, they produce distinct paths, reflecting school contextual differences. It appears that the single-mindedly academic, competitive environment of TOPS mimics the predominant patterns of adult success linked to gender inequality, so that males responding to it tend to be more traditional. Assertive girls in this environment tend to pursue illegitimate outlets. Conversely, in the differentiated environment of CENTRAL there seems to exist some correspondence between school attachment and gender-egalitarian beliefs. In this setting aggressive, success-driven girls have a higher probability of delinquent involvement but they also find other legitimate paths of behavior.

In conclusion, the findings of this exploratory study suggest that a highly competitive school environment is likely to produce higher levels of delinquency for both males and females, albeit for different reasons. In an environment where academic success is defined as an exclusive goal, inept students will more acutely feel their lack of success and therefore search for alternative careers (Figueira-McDonough, 1983; Mann, 1981). Such alternatives are unlikely to be available in schools dominated by a single defini- 
tion of success; illegitimate paths thereby become an attractive option. The more an organization ties its reputation to a specific goal, the greater the proportion of its resources committed to the implementation of the goal (Perrow, 1961). It is therefore to be expected that the school will invest disproportionately in students showing greater academic promise. This, in turn, further restricts legitimate opportunities for other students. The study by Porter $e t$ al. (1982) on Canadian public schools lends support to this interpretation.

In view of the current movement demanding a stricter " 3 rs" orientation in high schools as well as tougher grading systems, such unanticipated consequences should be considered. By enforcing uniform academic programs and absolute evaluation of students with different potential, we might not only upgrade education but also create clearly identified failures and possibly increase alienation and delinquency among adolescents. ${ }^{11}$

The competitive system proposed also necessarily promotes individualism and might atomize the student body, so that for successful students the school becomes merely a stepping-stone toward greater successes and for the unsuccessful an obstacle to their aspirations. In either case, school attachment can be expected to be low (as in TOPS), automatically decreasing the normative influence of the school.

To the extent that TOPS can be taken as typical of upper middle-class schools subscribing to an academic competitive orientation, the findings are also suggestive of the negative implications of such an environment for female sttudents. There is quite a bit of evidence pointing to a direct relationship between gender-egalitarian attitudes and class among women (Herzog and Bachman, 1982; Mason et al., 1976; Thorton and Freedman, 1979). Since gender roles tend to become established in adolescence (Condry, 1984) and the push of a feminist orientation is toward what Rebecca et al. (1976) calls sex role transcendence, behavioral reinforcers of the new gender roles are expected to be doubly important for this group of girls.

\section{REFERENCES}

Aultman, M. G. (1979). Delinquency causation: A typological comparison of path models. $J$. Criminal Law Criminol. 70(2): 152-163.

Barton, W., and Figueira-McDonough, J. (1985, March). Attachments, gender and delinquency. Deviant Behav. 6: 119-144.

Barton, W. H., Figueira-McDonough, J., and Sarri, R. (1982). Female delinquency: A multilevel analysis. Report Phase II. Office of Juvenile Justice and Delinquency Prevention, U.S. Department of Justice, Washington, D.C.

\footnotetext{
"In their study of the impact of schools on mental health, Kellam et al. (1975) found that failure in school tasks was directly related to low self-esteem and to maladaptive behavior.
} 
Bernard, T. J. (1984). Control criticisms of strain theories: An assessment of theoretical and empirical adequacy. J. Res. Crime Delinq. 12(4): 353-372.

Chester, N. L. (1983). Sex differentiation in two high school environments: Implications for career development among black adolescent females. $J$. Social issues 39(3): 29-40.

Coleman, J. S. (1969). A brief summary of the Coleman report. In Harvard Educational Review (ed.), Equal Educational Opportunity. Harvard University Press, Cambridge, Mass.

Coleman, J. S. (1972). The evaluation of equality of educational opportunity. In Mosteller, F., and Moynihan, D. P. (eds.), On Equality of Educational Opportunity. Random House, New York.

Condry, J. C. (1974). Gender identity and social competence Sex Roles 11(5/6)): 485-511.

Dembo, D. J. (1984). Longitudinal study of the crime-work-ability interrelationship. Paper presented at the annual meeting of the American Society of Criminology, Cincinnati, Ohio.

Elliott, D., and Ageton, S. (1980). Reconciling differences in estimates of delinquency. Am. Sociol. Rev. 45: 95-110.

Elliott, D., and Voss, H. L. (1974). Delinquency and Dropout. D. C. Heath, Lexington, Mass.

Eve, R. A. (1978). A study of the efficacity and interactions of several theories for explaining rebelliousness among high school students. J. Criminal Law Criminol. 69(1): 115-125.

Farnworth, M., and Horan, P. M. (1980). Separate justice: An analysis of race differences in court processes. Social Sci. Res. 9: 381-399.

Figueira-McDonough, J. (1983). On the usefulness of Merton's anomie theory: Academic failure and deviance among high school students. Youth and Society 14(3): 259-279.

Figueira-McDonough, J. (1984). Feminism and delinquency: In search of an illusjve link. Brit. J. Criminol. 24(4): 325-342.

Figueira-McDonough, J. (1985). Gender, race and class: Differences in levels of feminist orientation. J. Appl. behav. Sci. 21(2): 121-142.

Figueira-McDonough, J., and Selo, E. (1980). A reformulation of the equal opportunity explanation of female delinquency. Crime Deling. 26(3): 333-343.

Figueira-McDonough, J., Barton, W., and Sarri, R. (1981). Normal deviance: Gender similarities in adolescent subcultures. In Warren, M. Q. (ed.) Comparing Female and Male Offenders. Sage, Beverly Hills, Calif.

Flangan, J. C. (1962). Studies of the American High School. Project Talent Office, University of Pittsburgh, Pittsburgh, Penn.

Gold, M. and Petronio, R. J. (1980). Delinquent behavior in adolescence. In Adelson, J. (ed.), Handbook of Adolescent Psychology. John Wiley \& Sons, New York.

Goodland, J. (1984). A Place Called School. McGraw-Hill, New York.

Goodman, S. M. (1959, March). The Assessment of School Quality. New York State Education Department, Albany, N.Y.

Hargreaves, D. H. (1967). Social Relations in a Secondary School. Routledge and Kegan Paul, London.

Herzog, A. R. and Bachman, J. G. (1982). Sex role attitudes among high school seniors: Views about work and family roles. Research Report Series. Survey Research Center, Institute for Social Research, The University of Michigan, Ann Arbor, Mich.

Hindelang, M. J., Hirschi, T., and Weis, J. (1979). Correlates of deqlinquency: The illusion of discrepancy between self-report and official measures. Am. Sociol. Rev. 44: 995-1014.

Johnson, R. E. (1979). Juvenile Delinquency and Its Origins. Cambridge University Press, Cambridge.

Johnston, L. (1973). The American high school. Youth in Transition Working Paper 9. Institute for Social Research, The University of Michigan, Ann Arbor, Mich.

Kaufman, D. R., and Richardson, B. L. (1982). Achievement and Women: Challenging the Assumptions. The Free Press, New York.

Kellam, S. G., Branch, J. D., Agrawal, K. C., and Fensminger, M. E. (1975). Mental Health and Going to School. University of Chicago Press, Chicago, Ill.

Kelly, D. H. (1978). How the School Manufactures Misfits. New Cal Publication, South Pasadena, Calif.

Kreps, J. (1971). Sex in the Market Place: American Women at Work. Johns Hopkins University Press, Baltimore, Md. 
Mann, D. W. (1981). Age and differential predictability of delinquent behavior. Social Forces 60: $97-113$.

Mason, K. O., Czajka, J. L. and Arber, S. (1976). Change in U.S. women's sex role attitudes, 1964-1974. American Sociol. Rev. 41: 573-596.

Matthei, J. A. (1982). An Economic History of Women in America: Women's Work, The Sexual Division of Labor and The Development of Capitalism. Schocken Books, New York.

Meyer, J. W., and Rowan, B. (1977). Institutionalized organizations: Formal structure as myth and ceremony. Am. J. Sociol. 83(2): 340-363.

Parelius, A. P. (1975). Emerging sex-role attitudes, expectations and strains among college women. J. Marriage Family 37: 146-153.

Parsons, J. E. (1976). Cognitive-developmental factors in emerging sex differences in achievementrelated expectancies. J. Social Issues 32(3): 47-62.

Parsons, J. E., Frieze, I. H. and Ruble, D. N. (1976). Introduction. J. Social Issues 32(3): 1-7.

Perrow, C. (1961). The analysis of goals in complex organizations. Am. Sociol. Rev. 26: 856-866.

Pink, W. T. (1978). Rebellion and success in the high school. Contemp. Educ. 49: 78-84.

Pink W. T. (1984). Schools, youth, and justice. Crime Deling. 30(3): 439-461.

Polk, K. (1975). Schools and the delinquency experience. Criminal Justice Beahv. 2(4): 315-338.

Polk, K., and Schaffer, W. E. (1972). Schools and Delinquency. Prentice-Hall, Englewood Cliffs, N.J.

Porter, J., Porter, M., and Bushen, B. R. (1982). Stations and Callings: Making it Through the School System. Methuen, Toronto, Canada.

Powell, B., and Jacobs, J. A. (1984). The prestige gap: Differential evaluations of male and female workers. Work and Occupations $11(3): 283-308$.

Rebecca, M., Hefner, R., and Oleshansky, B. (1976). A model of sex role transcendence. $J$. Social Issues 32(3): 197-206.

Reubel, R., Brenner, R. N., Jones, C., and Kravitz, M. (1979). Crime and disruption in School; A Selected Bibliography. United States Department of Justice, law Enforcement Assistance Administration, National Institute of Law Enforcement and Criminal Justice.

Rist, R. (1970). Social class and teacher expectation. Harvard Educ. Rev. 49: 411-451.

Runkel, P. J., and McGrath, J. E. (1972). Research and Human Behavior: A Systematic Guide to Method. Holt, Rhinehard and Winston, New York.

Rutter, M., Maughan, B., Mortimore, P., Ouston, J., and Smith, A. (1979). Fifteen Thousand Hours: Secondary Schools and Their Effects on Children. Harvard University Press, Cambridge, Mass.

Screiber, E. M. (1978). Education and change in American opinions on a woman president. Public Opinion $Q$. 42: 171-182.

Shaicoft, M. F. (1967). The High School Years: Growth in Cognitive Skills. Project Talent Office, University of Pittsburgh, Pittsburgh, Penn.

Stinchcombe, A. (1964). Rebellion in a High School. Quadrangle, Chicago, Ill.

Thornton, A., and Freedman, D. (1979). Changes in the sex role attitudes of women, 1962-1977: Evidence from a panel study. Am. Sociol. Rev. 44: 831-842.

Treiman, D. J., and Hartman, H. (1981). Women, Work and Wages: Equal Pay for Jobs of Equal Value. National Academy Press, Washington, D.C. 